\title{
PAPERS
}

\section{Mild analgesics and the accident and emergency department-cost and safety more important than potency?}

D. W. YATES, G. S. LAING, K. PETERS AND K. KUMAR* Accident and Emergency Department, Hope Hospital (University of Manchester School of Medicine), Salford

\section{SUMMARY}

A prospective controlled trial involving over 1000 patients did not reveal any difference between four drugs commonly used in accident and emergency departments for the relief of mild to moderate pain. There were no significant variations in therapeutic effect, side-effects or patient compliance. When considering the supply of analgesics which may be no more potent than those available without prescription from retail chemists, cost and safety are more important than analgesic effect. By restricting the choice of analgesics available, the accident and emergency department should be able to increase awareness among its staff of the actions and side-effects of a small number of prescribed drugs and to contain costs.

\section{INTRODUCTION}

Doctors working in accident and emergency departments need clear guidelines on the choice of mild analgesics if consistent, safe and effective treatment is to be provided. Berbatis et al. (1982) have shown that a drug bulletin can achieve a significant improvement and consolidation of analgesic prescribing habits in a district hospital, but the influence is temporary. Similarly, withdrawal of potentially dangerous or ineffective drugs does not always have the desired long-term effect of increasing the use of safer preparations (Shenfield et al., 1980). New products may fill the gap and subsequently be found to be less desirable than their discredited predecessors.

The formulation of a departmental policy agreed by consensus and binding on all 
members of staff has obvious advantages. The variety of drugs held in stock is reduceg and more experience is gained of the efficacy and side-effects of a small number of regularly used analgesics. Costs are held down and the risk of prescription errops minimized.

However, it is not easy to assess the relative therapeutic value of drugs to be includeg in such a policy. A review of the extensive literature (Nicholson et al., 1980) did net reveal any particular analgesics as being clearly the most appropriate. Analgesic tria施 often use small numbers of patients and do not control all relevant variables. Most a not concerned with the unprepared patient typically seen in an accident and emergency department.

A large controlled trial was therefore conducted in an attempt to grade the therapeutic value of four of the analgesics currently used in such departments for the treatment of mild to moderate pain. Pain severity was assessed by interview and by 9 consideration of the diagnosis. Patients complaining of severe pain and those who were thought likely to develop it were excluded from the trial and were usually given opiates.

\section{METHODS}

Patients attending the accident and emergency department with conditions which we $\frac{3}{9}$ considered to produce mild or moderate pain were entered on to the trial if an analgesic prescription was thought appropriate.

The following groups were excluded:

- hospital admissions

- patients already receiving analgesics, anticoagulants, sedatives, psychoactive drugg or steroids

- patients with a history of peptic ulceration

- patients with known relevant allergies

- pregnant women

- children under 16 years of age.

Four commonly used drugs were chosen to represent the wide range of analgesics available for the treatment of somatic pain. Dosages were calculated from the Manufacturers Data Sheets to provide relief from 'moderate pain'.

- Fenoprofen (Progesic) $\mathbf{4 0 0} \mathrm{mg}$ t.d.s. Non-steroidal anti-inflammatory drug Promoted for the relief of post-operative, post-partum and traumatic pain.

- Mefenamic acid (Ponstan Forte) $500 \mathrm{mg}$ t.d.s. Non-steroidal anti-inflammatory drug. Promoted for the relief of mild to moderate pain including muscular traumatic and dental pain.

- Paracetamol $1000 \mathrm{mg}$ q.d.s. Analgesic without demonstrable anti-inflammatorion effect. Promoted for the relief of mild to moderate pain of varying aetiology.

- Zomepirac (Zomax) $100 \mathrm{mg}$ q.d.s. Non-steroidal anti-inflammatory dru民్ Promoted for the relief of all forms of moderate pain.

The tablets were boxed and numbered in random sequence by the hospital pharmacy and stocked in the accident and emergency pharmacy. Each box contained sufficier tablets for 3 days at the recommended dosage. A sealed envelope on the pharmacy waft 
contained the code which allowed the contents of a particular box to be identified in an emergency.

The doctor prescribed 'routine analgesia' on the patient's treatment chart and was unaware of the specific drug subsequently dispensed by the nurse. The patient was also given a questionnaire (bearing the same number as the box) to be returned after 3 days in a reply paid envelope. If no reply was received within 3 weeks another questionnaire was sent.

The purpose of the trial was explained to all patients and verbal consent obtained. The local Ethical Committee approved the design of the investigation.

\section{RESULTS}

A total of 19220 new patients were treated by the accident and emergency service in Salford during the period of this study. A total of 1585 eligible patients required mild analgesia and were entered into the trial. Of the 1103 patients who returned the questionnaire, 79 had not taken any of the prescribed tablets. This left a data base of 1024 patients. The four analgesics were equally represented in each of these totals (Table 1). The severity of the initial pain as described by the patient is given in Table 1. None had sufficient pain to warrant opiate or similar strong analgesia.

Figure 1 summarizes the degree of pain relief reported by patients in the four pain categories subdivided according to analgesic prescribed.

The raw data on which Fig. 1 is based were subjected to statistical analysis to identify any significant differences in response which could be attributed to differences in medication. Kendall's rank sum test for non-parametric data was used (Kendall, 1955). No significant differences in efficacy were found between any drug treatments (range $r=0.9011$ to $r=0.9948$ ). Subsets of patients with sprains (261), fractures (212) and contusions (347) were formed and examined separately. No significant differences in responses were found in those patients with contusions (range $r=0.8268$ to $r=0.9983$ ) or fractures (range $r=0.8142$ to $r=0.9989$ ). The responses of patients with sprains were more varied. They reported more relief with zomepirac than with mefenamic acid $(r \neq 0.3838)$ and more relief with paracetamol than with fenoprofen $(r=0.4962)$.

Table 1 The severity of initial pain reported by patients taking each analgesic

Mefenamic acid Zomepirac Fenopropen Paracetamol

\begin{tabular}{lrrrr}
\hline No. of patients entered on trial & 273 & 278 & 270 & 282 \\
No. of patients who did not take tablets & 19 & 20 & 15 & 17 \\
No pain & 2 & 5 & 6 & 4 \\
Mild pain & 53 & 55 & 62 & 59 \\
Moderate pain & 122 & 125 & 117 & 131 \\
Severe pain & 96 & 93 & 85 & 88 \\
\hline
\end{tabular}



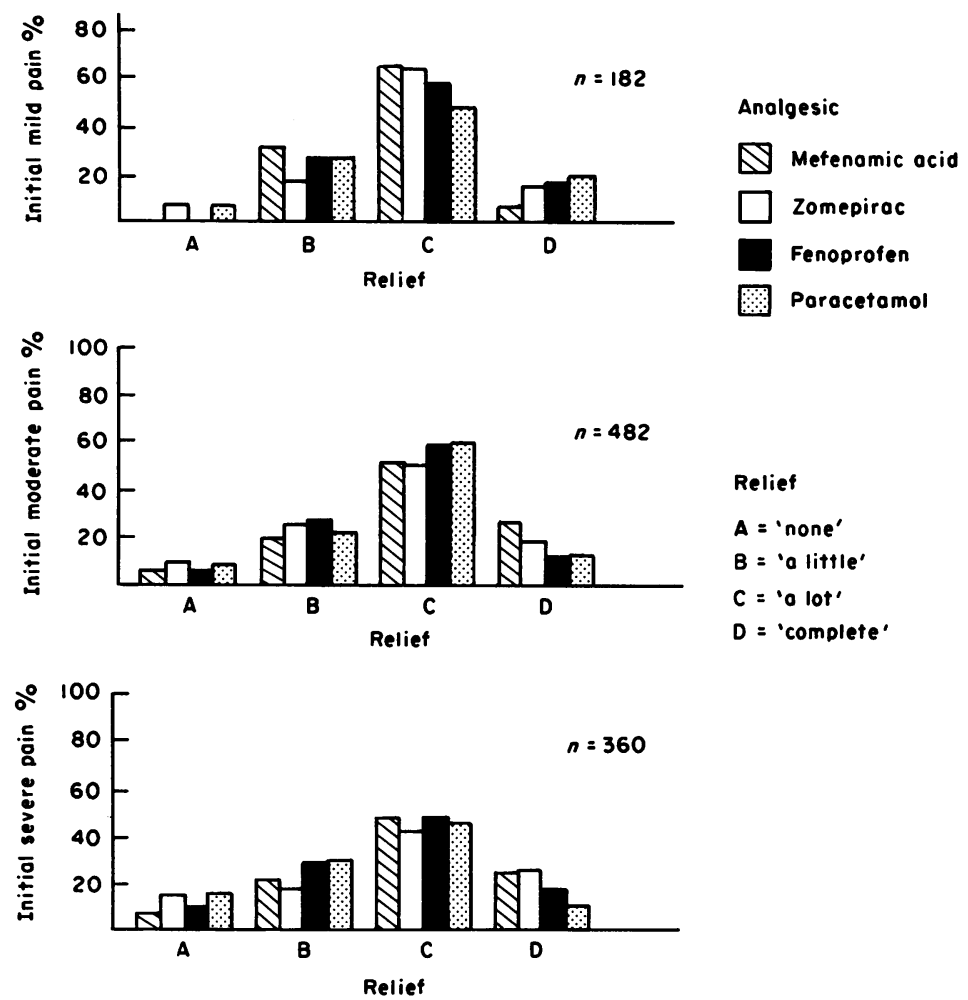

Fig. 1 Influence of analgesic on perceived pain.

However, cross comparisons did not reveal any significant differences between an other pairs and did not allow the drugs to be ranked in any order of efficacy.

Figure 2 shows the incidence of patients requesting further supplies of analgesic from their general practitioners, subdivided according to initial drug prescribed. There is no significant difference between the drug subgroups.

A wide variety of mild side-effects was reported with each drug. Details are given io Table 2. No trends were discernable. The overall incidence of side-effects was similar for each drug.

Table 2 Number of side-effects reported for each drug

\begin{tabular}{|c|c|c|c|c|}
\hline Side-effect & $\begin{array}{l}\text { Mefenamic acid } \\
\quad n=253\end{array}$ & $\begin{array}{c}\text { Zomepirac } \\
n=259\end{array}$ & $\begin{array}{c}\text { Fenopropen } \\
n=225\end{array}$ & $\begin{array}{c}\text { Paracetamol } \\
n=265\end{array}$ \\
\hline Drowsiness & 15 & 16 & 18 & 16 \\
\hline Nausea & 8 & 9 & 9 & 10 \\
\hline Stomach upset/diarrhoea & 1 & 4 & 9 & 6 \\
\hline Dizziness & 2 & 5 & 2 & 1 \\
\hline Headache & 1 & 3 & 2 & 2 \\
\hline Skin rash & 2 & 3 & - & 2 \\
\hline Other & 6 & 4 & 3 & 6 \\
\hline Total & 35 & 44 & 43 & 43 \\
\hline
\end{tabular}




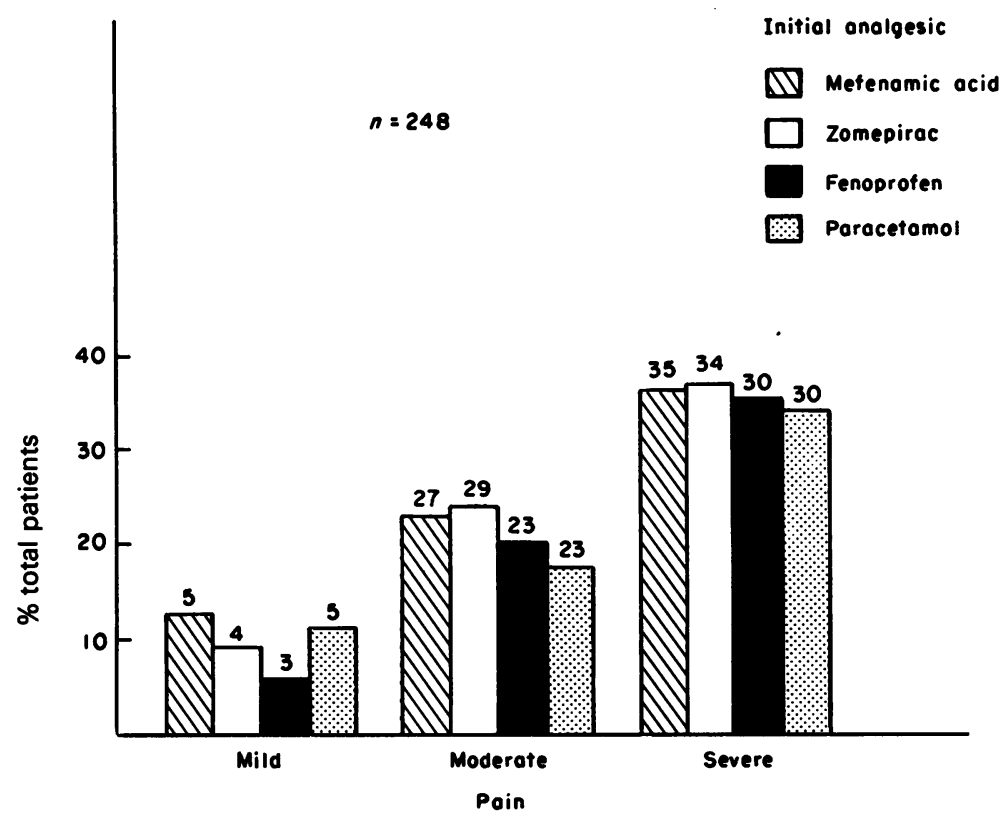

Fig. 2 Patients requiring additional analgesics.

\section{DISCUSSION}

The pharmaceutical industry continues to increase the number of drugs available for the relief of mild and moderate pain. Literature presented to accident and emergency staff by their representatives often cites comparative trials showing the advantages of a new product over currently prescribed drugs. A quick assessment of the scientific value of this information is often impossible because of the variation in methodology between trials and the vagueness of the subjective end-point. Most evaluations have been conducted on in-patients with post-partum pain (Sunshine, 1980), chronic cancer pain (Wallenstein \& Houde, 1975) or post-operative pain (Evans et al., 1982; Tammisto \& Tigerstedt, 1980), or on out-patients attending dental (Lokken \& Skjelbred, 1980; Cooper \& Beaver, 1974) or general medical (Graffenreid \& Nüesch, 1980) clinics. Analgesic trials on out-patients with post-traumatic pain are difficult to set up and are often restricted to small numbers of patients in unmatched groups. Claims of statistical significance may be invalid due to the use of inappropriate tests.

A total of 1585 patients were admitted to this trial. The four therapeutic groups contained similar numbers of patients (Table 1) with similar types of injury. There was a $70 \%$ response rate equally divided amongst the four groups.

The results reveal no difference between any of the four drugs with respect to therapeutic benefit (Fig. 1) or side-effects (Table 2). The differences between two pairs of drugs in the patients with sprains could not be substantiated by closer examination of 
the data. It is inevitable that differences or associations of statistical significance will ${ }_{6}^{\mathrm{D}}$ occur in any trial if there are enough subsets and enough cross tabulations. 'Dataz dredging' in this way usually produces spurious conclusions.

Inclusion of a placebo in the trial would have clearly confirmed the sensitivity of the $\overrightarrow{\vec{s}}$ method. However, there is an extensive literature comparing favourably the analgesics? used in this trial with placebo (Evans et al., 1982; Vaidya et al., 1974; Winnem et al.,음 1981) and it was not considered ethically justifiable to withhold treatment to recently

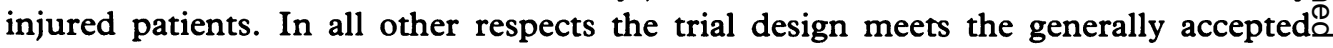
criteria established by Wallenstein \& Houde (1975). Table 1 and Fig. 2 provide goodœ circumstantial evidence that the questionnaire was able to discriminate between both $\vec{\circ}$ the severity of the initial pain and relief obtained by analgesia.

Stableforth (1977) and Sleet \& Khan (1980) addressed the concern which had beeno expressed about the use of dextropropoxyphene in the accident and emergency 3 . department. In controlled trials they showed that mefenamic acid was equally effectiveand had fewer side-effects. However, their groups were small and were not controlled: for diagnosis. In the present study no differences were demonstrable in the analgesic $\vec{\theta}$ action of four drugs, even when comparisons were confined to patients with specific $\fallingdotseq$ diagnoses (contusions, sprains, fractures).

The results of this trial suggest that the choice of a mild analgesic cannot be made on the basis of therapeutic effect. Other criteria must be taken into account in formulating $₫$ an analgesic policy.

Physiotherapy, splintage and counter-irritation may reduce the need for analgesics. Some patients do not have pain after quite major injuries. Others experience it on $y^{\circ}$ after a few hours. These factors will influence the prescription of analgesics.

Side-effects are also very important considerations, especially when the underlying condition is not serious and is usually self-limiting. It may be some years before $\frac{3}{0}$ significant but rare complications are attributed to a new drug. This is highlighted by⿳亠丷厂犬 reports of deaths following zomepirac medication in the United States (Anon., 1983), $\stackrel{\circ}{\circ}$ which were published after this trial had been completed.

Cost is an additional factor. Currently available drugs marketed for the relief of mild 3 to moderate pain vary in price from under $4 p$ to over $80 p$ for one day's supply. The cost of drugs used in this trial varied from $5 \mathrm{p}$ to $44 \mathrm{p}$. Cost is an important consideration in an accident and emergency department, which may supply up to 10000 analgesic 3 . prescriptions each year.

\section{REFERENCES}

Anon. (1983) Zomax withdraw from market after fatal reactions. The Pharmaceutical fournal 230, 299.

Berbatis C. G., Maher M. J., Plumridge R. J., Stoelwinder J. U. \& Zubrick S. R. (1982) Impact of a drug. bulletin on prescribing oral analgesics in a teaching hospital. American fournal of Hospital Pharmacy 39, N 98-100.

Cooper S. A. \& Beaver W. T. (1974) A model to evaluate mild analgesic in oral surgery outpatients. Clinical Pharmaceutical Therapy 15, 565-570.

Evans P. J. D., McQay H. J., Rolfe M., O’Sullivan G., Billingham R. E. S. \& Moore R. A. (1982) Zomepirac, $\frac{\mathscr{C}}{\Phi}$ placebo and paracetamol/dextropropoxyphene combination compared in orthopaedic post-operative pain. $\stackrel{\mathcal{O}}{-}$ British fournal of Anaesthesia 54, 927-933. 
Graffenreid B. V. \& Nüesch E. (1980) Non-migrainous headache for the evaluation of oral analgesics. British fournal of Clinical Pharmacology 10, Suppl., 225S-231S.

Kendall M. G. (1955) Rank Correlation Methods. 2nd edition. London, Griffin.

Lokken P. \& Skjelbred P. (1980) Analgesic and anti-inflammatory effects of paracetamol evaluated by bilateral oral surgery. British fournal of Clinical Pharmacology 10, Suppl., 253S-260S.

Nicholson P. A., Prescott L. F. \& Coulston F. (eds) (1980) Proceedings of a Symposium on Mild Analgesics, October 1979. British fournal of Clinical Pharmacology 10, Suppl., 209S-412S.

Shenfield G. M., Jones A. N. \& Patterson T. V. (1980) Effects of restrictions on prescribing patterns on dextropropoxyphene. British Medical fournal 281, 651-653.

Sleet R. A. \& Khan M. A. (1980) Comparative study of mefenamic acid and dextropropoxyphene plus paracetamol in an A \& E Department. Current Medical Research and Opinion 7, 77-84.

Stableforth P. G. (1977) Mefenamic acid and dextropropoxyphene with paracetamol as analgesics in the Accident Department. Current Medical Research and Opinion 5, 189-191.

Sunshine A. (1980) Clinical evaluation of mild analgesics in post partum pain. British fournal of Clinical Pharmacology 10, Suppl., 235S-237S.

Tammisto T. \& Tigerstedt I. (1980) Mild analgesics in post-operative pain. British fournal of Clinical Pharmacology 10, Suppl., 347S-350S.

Wallenstein S. L. \& Houde W. D. (1975) The clinical evaluation of analgesic effectiveness. In Methods of Narcotic Research. Ehrenrreiss \& Neidle (eds). New York, Marcel Dekker.

Winnem B., Samstad B. \& Breivik H. (1981) Paracetamol, tiarimide and placebo for pain relief after orthopaedic surgery. Acta Anaesthesiologica Scandinavica 25, 209-214.

Vaidya A. B., Sheth M. S., Manghani K. K., Shroff P., Vora K. K. \& Sheth U. K. (1974) Double blind trial of mefanamic acid, aspirin, and placebo in patients with post-operative pain. Indian fournal of Medical Science 12, 532-536.

Received 9 May 1984; editorial comments to authors 11 May 1984; accepted for publication 29 May 1984 